
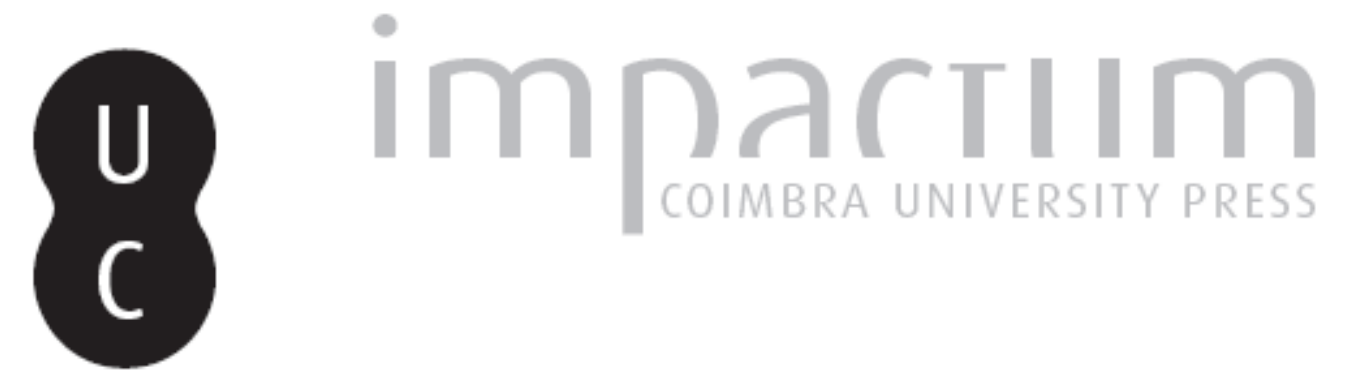

Um capitel de ara paleocristão (?) no Museu de Beja

Autor(es): $\quad$ Machado, Ana Goulão

Publicado por: Imprensa da Universidade de Coimbra

URL persistente:

URI:http://hdl.handle.net/10316.2/45551

DOI:

DOI:https://dx.doi.org/10.14195/1647-8657_29_9

Accessed : $\quad$ 26-Apr-2023 14:32:12

A navegação consulta e descarregamento dos títulos inseridos nas Bibliotecas Digitais UC Digitalis, UC Pombalina e UC Impactum, pressupõem a aceitação plena e sem reservas dos Termos e Condições de Uso destas Bibliotecas Digitais, disponíveis em https://digitalis.uc.pt/pt-pt/termos.

Conforme exposto nos referidos Termos e Condições de Uso, o descarregamento de títulos de acesso restrito requer uma licença válida de autorização devendo o utilizador aceder ao(s) documento(s) a partir de um endereço de IP da instituição detentora da supramencionada licença.

Ao utilizador é apenas permitido o descarregamento para uso pessoal, pelo que o emprego do(s) título(s) descarregado(s) para outro fim, designadamente comercial, carece de autorização do respetivo autor ou editor da obra.

Na medida em que todas as obras da UC Digitalis se encontram protegidas pelo Código do Direito de Autor e Direitos Conexos e demais legislação aplicável, toda a cópia, parcial ou total, deste documento, nos casos em que é legalmente admitida, deverá conter ou fazer-se acompanhar por este aviso. 
FACULDADE DE LETRAS

INSTITUTO DE ARQUEOLOGIA

CONIMBRIGA

VOLUME XXIX

UNIVERSIDADE DE COIMBRA

1990 
ANA GOULÃo MACHADO
Estudante de História da Arte — FLUC

UM CAPITEL DE ARA PALEOCRISTÃO (?) NO MUSEU DE BE JA

«Conimbriga», XXIX, 1990, 137-145

RESUMO: O presente estudo versa sobre um capitel existente no Museu de Beja e tenta resolver, através de uma análise iconográfica, o problema da sua origem e datação. Para tanto, tomam-se em consideração os motivos da decoração e o seu significado simbólico.

A conclusão que se extrai é a de que o capitel deve ser atribuído à época paleocristã.

ABSTRACT: The object of the present study is a capital belonging to the museum of Beja. Using an iconographie analysis that takes into accounte the omamen tal motives and their symbolic meanings, the author tries to find its origin and epoch. The conclusion is that the capital should de considered as early Christian. 
(Página deixada propositadamente em branco) 


\section{UM CAPITEL DE ARA PALEOCRISTÃO (?) NO MUSEU DE BEJA}

Encontra-se actualmente nos depósitos do Museu de Beja um capitel que se revela muito interessante pela iconografia que apresenta. Este trabalho pretende, através de uma análise pormenorizada da peça e das suas representações iconográficas, levantar hipóteses e oferecer sugestões para o estabelecimento da sua cronologia e filiação artística.

O capitel, cuja proveniência não lográmos identificar, está esculpido em mármore de Trigaches *. Apresenta figuras em relevo e é liso na face posterior, com filete a sublinhar o redondo do topo, que está encimado por um fóculo de $9 \mathrm{~cm}$ de diâmetro externo.

Tem $65 \mathrm{~cm}$ na base e $47 \mathrm{~cm}$ de altura total. Junto à base, com rebordo, quatro faixas inscritas que medem no seu conjunto $7 \mathrm{~cm}$ de altura e, de espessura, $27 \mathrm{~cm}$.

A decoração figurada da parte superior consta de duas aves afrontadas a beber de um vaso; de cada lado deste, duas rosetas. A distância que medeia entre a base do vaso (ou cálice) e o topo do capitel é de $23 \mathrm{~cm}$. A base do cálice tem $7 \mathrm{~cm}$, a roseta do lado direito mede $5,5 \mathrm{~cm}$ enquanto a do lado esquerdo tem $6 \mathrm{~cm}$. A distância que vai da roseta até ao extremo lateral do capitel é de $5,5 \mathrm{~cm}$.

Este capitel parece, à primeira vista, obra romana de um período já tardio, uma vez que se distinguem em cima dois toros simétricos e, no meio, uma elevação arredondada.

A iconografia, porém, faz pôr em questão a sua origem romana. Penso que a sua datação será de uma época posterior à queda do Império Romano do Ocidente. Este tipo de questões, surge, aliás, com frequência, em monumentos sem contexto arqueológico claro, como é o caso desta obra.

* Agradeço ao doutor José d'Encarnação os dados fornecidos quanto às dimensões e às características físicas do monumento, a respectiva fotografia e as sugestões para a elaboração deste trabalho no âmbito da cadeira de Epigrafia. 


\section{As aves afrontadas}

$\mathrm{Na}$ verdade, as aves afrontadas constituem um tema muito caro aos primeiros cristãos.

Em relação a este capitel, pode perguntar-se se as aves serão pombas ou pavões. Neste último caso, teríamos de ver no fílete que se prolonga, a representação da cauda. Inclino-me a pensar, no entanto, que se trata de pombas, uma vez que o pavão é geralmente representado de cauda aberta.

Tanto a pomba como o pavão aparecem em representações anteriores à escatologia cristã, como, por exemplo na tumulária romana $\left(^{1}\right)$, que vai atribuir a estes símbolos novos significados. O mesmo se passa em relação ao vaso (ou cálice) que foi, desde o início, um símbolo usado pelos cristãos. Como escreveu Justino Maciel, “a arte dos primeiros cristãos começa por se manifestar sobretudo pelo seu conteúdo, tomando de empréstimo à arte romana as diferentes componentes formais. Ela nos surge, assim, como uma nova linguagem dentro do discurso artístico romano, utilizando a mesma terminologia, o mesmo léxico, mas com uma mensagem diferente" $\left({ }^{2}\right)$.

A pomba tomou, ao longo dos tempos, vários significados.

No simbolismo judaico-cristão, a pomba (que com o Novo Testamento se assumirá como a imagem do Espírito Santo) é fundamentalmente um símbolo de pureza. Mas já na acepção pagã - que valoriza diferentemente a noção de pureza, não a opondo ao amor carnal mas associando-a ao mesmo tempo ao pássaro de Afrodite - representa a realização amorosa que o amante oferece ao objecto do seu desejo.

Estas simbologias - a cristã e a não-cristã — só diferem na aparência; daí que a pomba represente, muitas vezes, o que o homem tem de perdurável, ou seja, o seu princípio vital, a alma. Por isso, em certos vasos funerários gregos, ela é representada a beber de um vaso que simboliza a fonte da memória. É essa mesma imagem que surge na iconografia cristã: no relato do martírio de São Policarpo, por exemplo, aparece uma pomba a sair do corpo do santo depois da sua morte.

O Cfr. José d'Encamaçâo, Inscrições Romanas do Conventus Pacensis, Coimbra, 1984, inscrição n. ${ }^{\circ}$ 583: epitáfio de Comínia Avita, de 9 anos, proveniente de Eivas.

( ${ }^{2}$ " "Da arte romana à arte paleocristã. O sarcófago romano de Évora", Revista de Ciências Sociais e Humanas, Universidade Nova de Lisboa, 1989, pp. 97-98. 
Todo este simbolismo é, evidentemente, resultado da beleza e da graça desta ave, da sua brancura imaculada, da doçura do seu arrulhar $\left({ }^{3}\right)$.

\section{O vaso}

O vaso (ou, neste caso, o cálice) é um motivo decorativo largamente representado nos mosaicos romanos da Lusitânia, mormente na época tardia e, apesar de lhe podermos definir muitas variantes, o certo é que todas se poderão integrar "claramente na evolução para uma tipologia específica" (4).

A Igreja não podia, assim, esquecer o uso sistemático do vaso e da sua simbologia religiosa, muito ligada aos cultos iniciáticos por nítida influência das religiões orientais. Ao pôr de lado a circuncisão judaica, a Igreja vai adoptar um novo rito de iniciação - o baptismo. Desta sorte, o vaso surge, no Cristianismo, ligado ao ritual da purificação, ou seja, ao baptismo, e assume, por essa via, papel primordial na escatologia cristã.

Não admira, por consequência, que ele passe a ser encarado sob uma nova perspectiva: o vaso encerra, sob diferentes formas, o elixir; é um reservatório de vida. $\mathrm{O}$ facto de ser aberto no topo indica receptividade às influências celestes. Recorde-se, por outro lado, que, quando aparece esta representação de aves afrontadas a beber de um vaso, supõe-se que este possa conter água ou vinho - e estes dois elementos têm também diferente significado no discurso religioso.

$\mathrm{O}$ vinho significa, na ideologia católica, o sangue de Cristo; quem o beber viverá para a vida eterna. Geralmente associado ao sangue, tanto pela cor como pelo seu carácter de "essência" de planta, é, por conse-

$\left({ }^{3}\right)$ Quanto ao pavão, que também aparece em representações não-cristãs, atribui-se-lhe um profundo simbolismo cristão: simboliza a roda solar e é, deste modo, o símbolo da imortalidade; a sua magnífica e multicolor cauda aberta evoca deslumbrantemente o céu estrelado.

Assinale-se, ainda, que a iconografia ocidental representa, por vezes, os pavões a beberem do cálice eucarístico. Na Idade Média, são já representados de um e outro lado da árvore da Vida, símbolos da alma incorruptível e da dualidade psíquica do Homem. Apelidado de "animal dos cem olhos", o pavão tomou-se, pouco a pouco, o símbolo da beatitude eterna, da visão face a face de Deus com a alma.

Cfr. Chevalier, J. et Gheerbrant, A. Dictionnaire des Symbols, ed. Robert Laffont et ed. Jupiter, Paris, 1982.

$\left({ }^{4}\right)$ Justino Maciel, ob. cit., p. 108. 
guinte, a bebida da vida ou da imortalidade. Já na Grécia Antiga o vinho substituía o sangue de Dioniso e figurava a bebida da imortalidade.

A água tem a ver com tres temas dominantes: fonte da vida, meio de purificação, centro de regenerescéncia. Estes três temas encontram-se nas tradições mais antigas e formam as combinações mais variadas, ao mesmo tempo que as mais coerentes. Na tradição judaico-cristã, a água identifica-se, em primeiro lugar, com a origem da criação. Fonte de todas as coisas, ela manifesta o transcendente. Todavia, assim como todos os símbolos, a água pode ser encarada sob dois planos rigorosamente opostos, mas de forma alguma irredutíveis: é fonte de vida e de morte, criadora e destruidora. Todo o Antigo Testamento celebra a magnificência da água; o Novo Testamento receberá esta herança e saberá como utilizá-la.

Decoração bastante curiosa é, ainda, a que embeleza o vaso na sua parte superior. Trata-se, certamente, de uma simplificação da representação do crísmon, bastante estilizada, talvez por imperícia do artista. Não nos podemos esquecer de que os grandes centros culturais (Roma e, mais tarde, Constantinopla) estavam muito afastados, pelo que é natural que surgissem, nas províncias, "adulterações" dos modelos primitivos. Note-se que, na decoração deste vaso, o crísmon parece estar representado duas vezes.

\section{As rosetas}

As rosetas que neste capitel aparecem a ladear o vaso têm um significado muito singular.

Segundo Puig i Cadafalch (5), as crenças populares infiltram-se, paulatinamente, na alma do conquistador - que é, por sua vez, um pouco conquistado. Assim sendo, é natural que as rosetas, que primitivamente apareciam no imaginário popular como "medida profiláctica" para os vivos e protecção dos mortos, tenham passado para as representações colectivas de conquistadores. Na verdade, a rosácea é um dos temas decorativos mais vulgares da arte indígena, tanto peninsulari ${ }^{6}$ ) como além-pirenaica $\left({ }^{7}\right)$, pelo que não é de estranhar a sua representação aqui.

(5) L'Art Wisigothique et Ses Survivances, Paris, ed. F. de Noble, 1861, pp. 54-55.

(') Mantas, V., "Inscrições de Torres Vedras", Conimbriga, XXI, 1982, pp. 81-83.

$\left({ }^{7}\right)$ Cumont, F., Recherches sur le Symbolisme Funéraire des Romains, Bibliothèque Archéologique et Historique, tomo XXXV, Paris, 1945, p. 225. 
A rosácea poderá ser uma reminiscencia do culto de Júpiter qu gozava de grande aceitação na Lusitânia e na Tarraconense. A su; representação está, geralmente, associada ao culto solar, ligando-se à ideias astrais sobre a vida extraterrena. Esta iconografia da vida extrater rena está, aliás, muito de acordo com a escatologia vertical própria de Cristianismo ${ }^{8}$ ).

Mantêm, pois, o seu significado mágico, em contexto funerário. $\mathrm{Nc}$ realidade, este tipo de decoração aparece já em monumentos romanos e designadamente, em monumentos funerários, podendo ser interpretado como uma invocação aos deuses. É, portanto, natural que as rosetas estejam presentes neste capitel, cujo carácter funerário se poderá détectai na existência, no topo, de um fóculo que, na época romana, era utilizado para fazer libações, ou seja, para a prática de actos de purificação a favor do defunto.

\section{A distribuição da decoração}

Falta-nos referir um outro aspecto importante, que é a distribuição, na peça, dos elementos decorativos.

Com efeito, o capitel tem um eixo de simetria vertical, atribuível a influências orientais, designadamente à arte dos maravilhosos tecidos do Oriente, onde a simetria dos desenhos é factor preponderante. A grande preocupação em seguir um eixo de simetria é, de facto, aqui muito evidente. E o autor denuncia estar ao corrente dos modelos decorativos vigentes noutras paragens - o que, apesar de algumas "adulterações" dos modelos originais, patenteia, da sua parte, um considerável nível cultural.

\section{A iconografia cristã}

As observações atrás exaradas levam-nos, pois, a considerar nitidamente cristã a iconografia patente neste capitel. Claro está que os mencionados elementos já apareciam em monumentos anteriores aos dos primeiros cristãos; mas a sua conjunção num só monumento indicia preferencialmente uma leitura cristã.

( $\left.{ }^{8}\right)$ Blázquez, J. M., Primitivas Religiones Ibéricas, Tomo II, Religiones Prerromanas, Ed. Cristiandad, Madrid, 1983, pp. 269-270. 
Deste modo, as pombas parecem estar a beber um precioso líquido (água ou vinho), sendo o seu recipiente a fonte - o que significa que aquele que tem fé, que acredita na palavra divina, viverá eternamente. A alma que se alimenta da palavra de Deus, da Sua fonte, é purificada e pode ascender à vida eterna.

Perguntar-se-á como é que se explica, então, o facto de aparecerem, lado a lado, uma prática pagã (as libações) e uma iconografia cristã. Mas não podemos esquecer que o Cristianismo foi, desde cedo, confrontado - como dissemos — com um imaginário popular de práticas ancestrais, reflexo de crenças de origem pagã, que sobreviveram à cristianização e que, só mais tarde, foram finalmente absorvidas pela Igreja. Assim se explica que fé cristã e práticas pagãs perdurem longo tempo de mãos dadas — o que, de resto, ainda hoje acontece.

Será possível precisar-se melhor a cronologia do monumento?

Atribuição de datas precisas a este tipo de monumentos levanta, como se sabe, problemas. Ignoramos, com efeito, muitos dos elementos relevantes para uma datação precisa: desconhece-se, por exemplo, o contexto arqueológico em que a peça foi encontrada (se é que o tinha); não dispomos da parte inferior da ara que poderia conter a inscrição e proporcionar, assim, a análise do tipo de letra, o conhecimento do dedicante e do motivo da erecção do monumento. Resta-nos, portanto, recorrer uma vez mais - à iconografia e à tipologia.

Uma baliza cronológica será 313 , data do Édito de Milão. Na verdade, a religião cristã termina, então, a clandestinidade em que viviam os seus prosélitos. Ora, no capitel em exame, os símbolos cristãos não aparecem escamoteados, antes ostensivos - o que significa que a religião cristã já estava, à data da sua execução, devidamente legalizada.

A tipologia do monumento pode dar-nos, também, algumas indicações. Este tipo de capitéis eram geralmente postos no cimo de uma ara (altar composto por uma base, fuste e, naturalmente, um capitel) o que nos pode indicar uma reminiscência romana. Rejeitamos, assim, uma origem visigòtica: sabe-se que, na época visigòtica, a escultura aparece já associada à arquitectura (fruto de uma tradição anti-icónica), ou seja, servindo-se do suporte arquitectónico para emergir. O nosso capitel, ao integrar uma ara, valia só por si, independentemente de qualquer edificação, o que afasta a qualificação de escultura visigótica.

Talvez se possa, então, datar esta peça da época paleocristã, do período que medeia entre a "conversão" de Constantino (século IV) e o princípio do século VI. 
Para uma melhor compreensão e mais adequada integração histórica do monumento seria interessante verificar se na região sul do nosso País existem outros exemplares semelhantes. É que, de facto, por estar depositado no Museu de Beja, é natural que ele tenha sido encontrado ali perto.

A pesquisa que logrei efectuar permitiu-me identificar, na realidade, publicadas no segundo volume da História da Arte em Portugal, duas peças - uma placa triangular procedente de S. Miguel da Mota (Terena, Alandroal) e uma pilastra achada em Sines — que apresentam o mesmo tipo de iconografia, embora de uma época já posterior $\left({ }^{9}\right)$. Continuando a pesquisa, encontrei alguns mosaicos romanos com a representação das aves associadas ao cálice. Com efeito, no mosaico "EI Vilet" $\left({ }^{10}\right)$ e no de "Ramalete" $(\mathrm{n})$ estão presentes estes motivos.

Parece-me que esta iconografia era bastante frequente na Península, pelo que não é de estranhar o seu aproveitamento para a decoração do capitel de Beja, embora com uma intenção já cristã.

Este paralelismo, se denuncia, por um lado, uma tradição iconográfica que não é de todo estranha ao território actualmente português, e até peninsular, pode ajudar-nos, por outro, a entender o contexto e a significação deste capitel do Museu de Beja.

( $\left.{ }^{9}\right)$ Almeida, C. A. F., "A Arte da Alta Idade Média", in História da Arte em Portugal, voi 2, ed. Alfa, Lisboa, 1986, pp. 56 e 70.

$\left({ }^{10}\right)$ Cfr. J. M. Blázquez, G. Lopez Monteagudo, M. L. Neira-Jimenez, M.P. Sannicolas Pedraz, Corpus de Mosaicos de Espana, "Mosaicos de Lérida e Albacete", fase. VIII, Madrid, 1989, lám. 9.

$\left({ }^{n}\right)$ Cfr. J. M. Blázquez, M. A. Mesquiniz, Corpus de Mosaicos de Espana, "Mosaicos Romanos de Navarra”, fase. VII, Madrid, 1985, lám. 42. 


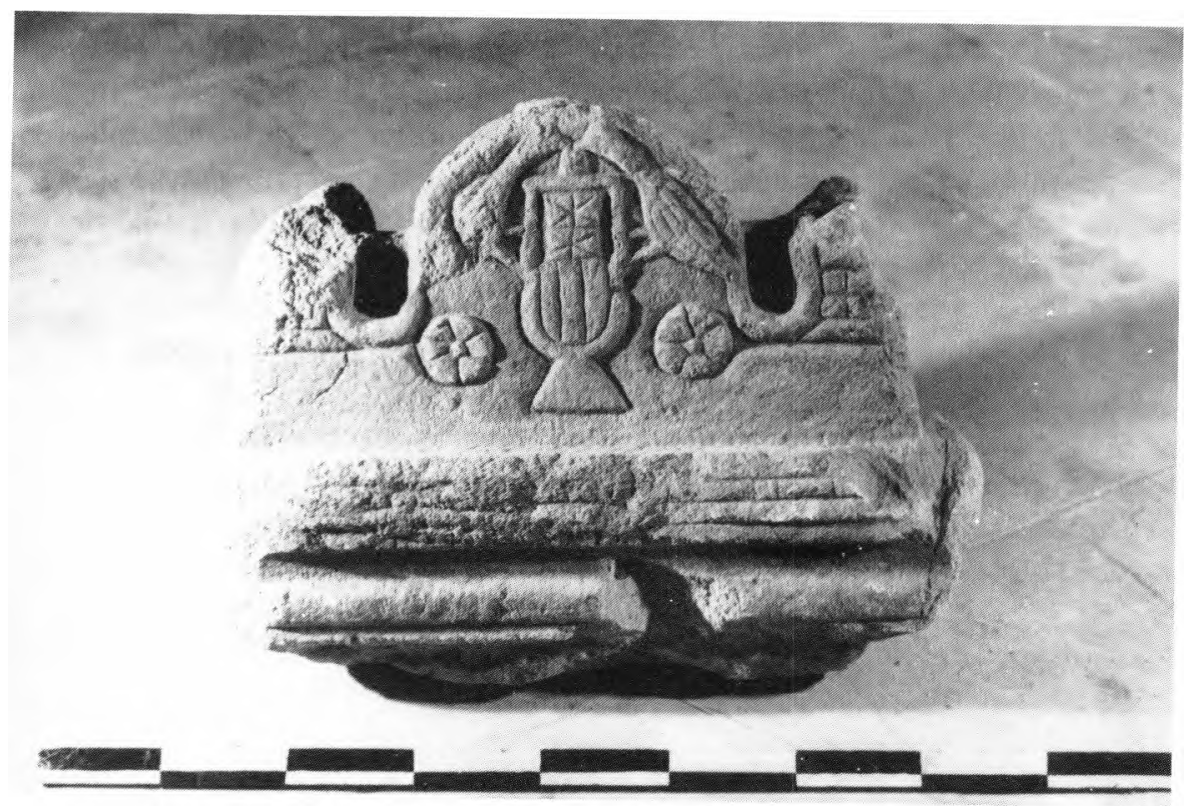

FIG. 1 